\title{
Perspectives of Hospitalized Older Patients About Practices of Intern Nurses
}

\author{
Belgüzar Kara ${ }^{*}$, Elif Gökçe Tenekeci², Elif Tuğba Sarı ${ }^{3}$ and Şerife Bayraktar ${ }^{3}$ \\ ${ }^{1}$ Department of Internal Medicine Nursing, Gulhane School of Nursing, University of Health Sciences, Turkey \\ ${ }^{2}$ Republic of Turkey Ministry of National Defence, Turkey \\ ${ }^{3}$ Gulhane Education and Research Hospital, Turkey
}

Submission: May 05, 2017; Published: May 25, 2017

*Corresponding author: Belgüzar Kara, Department of Internal Medicine Nursing, Gulhane School of Nursing, University of Health Sciences, Ankara, Turkey, Email: sb.kara@mynet.com

\section{Abstract}

Objective: This study aimed to determine the views of hospitalized older patients about practices of intern nurses (fourth-grade nursing students) and their related factors.

Methods: A cross-sectional study was performed among 70 adults aged 65 years or older hospitalized for different reasons in a tertiary hospital in Turkey. Data were collected by using a questionnaire form including socio demographic characteristics and the views about the intern nurses. Data analysis were conducted using descriptive statistics and Chi-square test.

Result: The majority of the older patients reported that the intern nurses got into communication with them and helped them to feel better $(92.4 \%)$ and the intern nurses respected for their privacy (86.9\%). Some older patients (35.7\%) reported that they would be worried if the intern nurses perform invasive interventions. The patients who perceived support for themselves and their caregivers from intern nurses were more likely to be aged 75 years or older $(\chi 2=20.01, p<0.001)$.

Conclusion: The results of the study showed that intern nurses mostly communicated with their older patients, informed them concerning the applications to be performed and respected their privacy. A better understanding of the views of hospitalized older patients about practices of intern nurses would help to develop effective interventions.

\section{Short Communication}

According to the estimates of the World Health Organization [1], the number of people aged 65 or older is projected to reach 1.5 billion (or $16.0 \%$ of the world's population) by 2050 , compared with 524 million (or $8.0 \%$ of the world's population) in 2010. Within this context, it is very important to provide comprehensive healthcare services for older adults. On the other hand, in-hospital risk factors such as low mobility, suboptimal continence care, and low nutrition consumption are related to functional decline at discharge and at 1-month follow-up in older adults hospitalized for nondisabling conditions [2]. Therefore, nurses play a key role in caring for older patients and their families [3-6]. However, studies have demonstrated that some undergraduate nursing students hold negative attitudes toward older adults $[7,8]$. To our knowledge, few studies have investigated how older patients perceived the care received from undergraduate nursing students in hospitals. This study aimed to determine the views of hospitalized older patients about practices of intern nurses (fourthgrade nursing students) and their related factors.

This cross-sectional study was conducted between March 2014 and May 2014. A convenience sample of hospitalized older patients was recruited from a tertiary hospital in Turkey. Patients aged 65 years or older, provided with the service by the intern nurses, hospitalized for at least 2 days, and those who were able to communicate in Turkish were included in this study. Patients with major psychiatric disease and cognitive impairment, and those with clinical instability were excluded from the study. Of the 110 eligible older patients, 70 (58.6\% female) agreed to participate (response rate: $63.6 \%$ ). This study was approved by the Hospital Ethical Committee, and written informed consents were obtained from participants before their enrollment. Data were collected by using a questionnaire form including socio demographic characteristics and the views about the intern nurses that was developed based on a comprehensive review of the literature. Data analysis were conducted using descriptive 
statistics and Chi-square test. A p value of less than 0.05 was considered statistically significant.

The mean age of the patients was $72.6 \pm 6.2$ years (range $=$ 65-88). Most of the patients were graduated from primary and secondary school (57.1\%) and high school (22.9\%). Forty nine hospitalized surgical patients (70.1\%) and twenty one medical patients $(29.9 \%)$ enrolled this study. The majority of the older patients reported that the intern nurses got into communication with them and helped them to feel better (92.4\%) and the intern nurses respected for their privacy (86.9\%). Interestingly, some older patients $(35.7 \%)$ reported that they would be worried if the intern nurses perform invasive interventions such as intravenous cannulation or taking a blood sample. It was found that most of them $(85.7 \%)$ would not feel uncomfortable to be provided with service by the intern nurses when they apply to the hospital next time. The patients who perceived support for themselves and their caregivers from intern nurses were more likely to be aged 75 years or older $(\chi 2=20.01, p<0.001)$.

The results of this study indicated that intern nurses mostly communicated with their older patients, informed them concerning the applications to be performed and respected their privacy. In order to decrease the concerns of the older patients caused by the invasive interventions of the intern nurses, it might be suggested to increase the applied training opportunities and to perform these applications under the supervision of clinic nurses. A better understanding of the views of hospitalized older patients about practices of intern nurses would help to develop effective interventions.

This work is licensed under Creative Commons Attribution 4.0 License

\section{Acknowledgment}

The authors thank all the patients who participated in this study.

\section{References}

1. World Health Organization (2011) Global health and aging. WHO, Geneva, Switzerland.

2. Zisberg A, Shadmi E, Gur-Yaish N, Tonkikh O, Sinoff (2015) Hospitalassociated functional decline: the role of hospitalization processes beyond individual risk factors. J Am Geriatr Soc 63(1): 55-62.

3. Coyle MA, Burns P, Traynor V (2017) Is it my job? The role of RNs in the assessment and identification of delirium in hospitalized older adults: An exploratory qualitative study. J Gerontol Nurs 43(4): 29-37.

4. Kara B (2009) A neglected risk factor in osteoporosis: Smoking Turkish J Geriatrics 12(1): 49-54.

5. Halvorsen K, Eide HK, Sortland K, Almendingen K (2016) Documentation and communication of nutritional care for elderly hospitalized patients: Perspectives of nurses and undergraduate nurses in hospitals and nursing homes. BMC Nurs 15: 70.

6. Fox MT, Butler JI (2016) Nurses perspectives on how operational leaders influence function-focused care for hospitalised older people. ] Nurs Manag 24(8): 1119-1129.

7. Söderhamn O, Lindencrona C, Gustavsson SM (2001) Attitudes toward older people among nursing students and registered nurses in Sweden. Nurse Educ Today 21(3): 225-229.

8. Sarabia-Cobo CM, Castanedo Pfeiffer C (2015) Changing negative stereotypes regarding aging in undergraduate nursing students. Nurse Educ Today 35(9): e60-e64.

\section{Your next submission with Juniper Publishers} will reach you the below assets

- Quality Editorial service

- Swift Peer Review

- Reprints availability

- E-prints Service

- Manuscript Podcast for convenient understanding

- Global attainment for your research

- Manuscript accessibility in different formats

( Pdf, E-pub, Full Text, Audio)

- Unceasing customer service

Track the below URL for one-step submission https://juniperpublishers.com/online-submission.php 